\title{
The digital divide and \\ single-gender undergraduate education in the UAE
}

\author{
Gilles Doiron
}

Zayed University, UAE

\section{Introduction}

A number of researchers have looked into the relationship between gender and differing experience with information and communication technology (ICT). Termed as a "gender divide" (Hafkin \& Huyer, 2006), "digital inequality" (DiMaggio et al., 2004) or "gender digital divide" (Huyer \& Mitter, 2003), this 'divide' is evident from studies that show lower numbers of women accessing and using ICT compared to men, and is considered to be associated with self-efficacy (confidence in one's own ability) in the use of ICT (Dhakal, 2009; Milis et al., 2008). Research on the effects of both gender and experience with computers and the internet (Sam et al., 2005; Usoro \& Abid, 2006), while not conclusive, has mostly reported that males have higher levels of computer user self-efficacy (Cassidy \& Eachus, 2002). This has lead researchers to suggest that, without redress, this situation would intensify and create new forms of inequality between women and men (United Nations, 2005; Hargittai \& Shafer, 2006).

In the United Arab Emirates (UAE), nationally funded secondary, vocational, college and university undergraduate education is conducted in single-gender settings: separate schools and campuses for women and men (Martin, 2005). This mirrors the social, religious and cultural values of the UAE, in which gender segregation is fundamental and differing roles, rules and expectations for women and men are the norm (Tubaishat et al., 2006).

For UAE females, using ICT to communicate outside their traditional boundaries may create conflict (Shen \& Shakir, 2009; Vodanovich et al., 2010). Shakir et al. (2008) point out that it is common practice for families to restrict females from having unmonitored contact with the outside world, and any transgression is viewed as "inappropriate and would negatively affect the reputation of the daughter, sister, or wife as well as her family" (p. 8). Conversely, boys and men benefit from a bias in the family decision making process, and are given priority when it comes to learning about and using computers (Zineddine \& Kindi, 2011). In light of these circumstances it is important that research focus on exploring and identifying the elements that help generate a 'gender digital divide' in the UAE.

\section{Methods}

With campuses in the two major cities of the United Arab Emirates, Zayed University (ZU) delivers its undergraduate program in single gender settings. During the 2011 Fall semester, $480 \mathrm{ZU}$ undergraduate students in first- and second-level General Education courses (404 female (84\%) and 76 male (16\%)) voluntarily completed a student ICT profile questionnaire. The gender ratio was proportional to the overall number of males and females enrolled in these courses, which, being obligatory General Education courses, include students from range of subject specializations. The paper questionnaire was distributed in class, and the students either completed it during class time or filled it in outside class and returned it to their teacher. All students who were present in class consented to filling in the questionnaire, and only a small number $(<5 \%)$ did not return it as requested. 
The questionnaire included demographics such as campus location, gender and age, and four sections of responses covering:

a) perceived competency using basic and specialized software (13 items)

b) frequency of computer usage and internet access (15 items)

c) frequency and type of Internet activity (24 items)

d) attitudes towards using computers and the Internet (22 items)

Measures of attitudes towards Internet and computer use were based on those of Torkzadeh \& Koufteros (1994); the computer user self-efficacy scale and web user self-efficacy scales used were those developed by Cassidy \& Eachus (2002; Eachus \& Cassidy, 2004). Responses for a), b) and c) were on a five point rank order scale and items in d) were on a five point Likert scale. The survey questionnaire is attached in the Appendix.

In order to examine differences associated with gender, SPSS non-parametric tests and discriminant function analysis (DFA) were conducted on the data. Since the data was not acquired through a controlled experimental approach, the independent-samples Mann-Whitney $U$ test was used (Fay and Proschan, 2010), and in order to ensure that statistically significant effects were worthy of further exploration, a calculation of effect size was conducted (Dunlap et al., 1996; Coe, 2002). The values obtained were rated according to Cohen's (1988) convention, and as Coe (2002) points out, $d$ values less than 0.5 are deemed inconsequential.

As well, the relationship between a truly dichotomous dependent variable, such as gender, and the means of an independent variable (IV) can be examined using a post-hoc DFA (Laforge, 1981). Similar to a one-way analysis of variance, the DFA looks at differences among groups of the dependent variable (in this case Gender), identifies variables that are related to group membership, classifies cases into groups with a better than chance degree of accuracy and predicts group membership from a set of predictors (Klecka, 1980).

\section{Findings}

The questionnaire was completed by 480 students, 404 female (84\%) and 76 male (16\%); 273 (57\%) of the sample were from the Abu Dhabi campus and 207 (43\%) were from the Dubai campus. The data shows that there were no statistically significant differences between campuses. Students were aged from 17 to 33 years (16 cases missing); the mean and mode of the age distribution was 20, and the standard deviation was 1.48 .

Table 1: Perceived competency (Mann-Whitney U test).

\begin{tabular}{|l|ccc|ccc|cc|}
\hline & \multicolumn{3}{|c|}{ Female } & \multicolumn{3}{c|}{ Male } & \\
\hline How competent are you with: & $\mathbf{N}$ & Mean & STDEV & $\mathbf{N}$ & Mean & STDEV & Sig. & $\begin{array}{c}\text { Effect } \\
\text { Size }(\boldsymbol{d})\end{array}$ \\
Presentation software & 400 & 4.49 & .77 & 76 & 3.97 & .77 & .000 & .7 \\
Concept mapping & 387 & 1.90 & 1.16 & 71 & 2.52 & 1.23 & .000 & .5 \\
Modeling software & 390 & 1.52 & .93 & 74 & 2.05 & 1.34 & .000 & .6 \\
\hline
\end{tabular}

Table 1 shows that while females presented more confidence in their competency using presentation software, they viewed themselves as less competent than their male counterparts when it came to 
specialized software like concept mapping and modeling applications. A DFA supports the findings of the Mann-Whitney $U$ test with presentation software and concept mapping as the top predictors of gender.

Table 2: Frequency of computer usage and internet access (Mann-Whitney $U$ test).

\begin{tabular}{|c|c|c|c|c|c|c|c|c|}
\hline \multirow{2}{*}{ 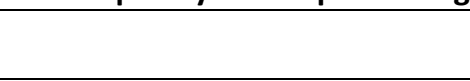 } & & & & \multirow{2}{*}{\multicolumn{3}{|c|}{ Male }} & \multirow[b]{3}{*}{ Sig. } & \multirow[b]{3}{*}{$\begin{array}{c}\text { Effect } \\
\text { Size }(d)\end{array}$} \\
\hline & & Female & & & & & & \\
\hline Do you use the computer to: & $\mathbf{N}$ & Mean & STDEV & $\mathbf{N}$ & Mean & STDEV & & \\
\hline Process text & 402 & 4.49 & .76 & 76 & 3.97 & .99 & .000 & .7 \\
\hline Prepare spreadsheets & 402 & 2.58 & 1.09 & 74 & 3.38 & 1.34 & .000 & .7 \\
\hline Access the Internet & 400 & 4.90 & .45 & 74 & 4.58 & .89 & .000 & .7 \\
\hline Author micro-worlds/sims & 392 & 1.28 & .68 & 70 & 1.76 & 1.00 & .000 & .7 \\
\hline Make concepts maps & 397 & 1.31 & .63 & 75 & 1.81 & 1.14 & .000 & .8 \\
\hline Model complex systems & 393 & 1.22 & .57 & 73 & 1.62 & 1.01 & .000 & .7 \\
\hline Write a computer program & 396 & 1.33 & .72 & 74 & 1.68 & 1.02 & .001 & .5 \\
\hline
\end{tabular}

Table 2 shows that females have a higher frequency of computer use than men for accessing the internet and word processing. However, males have significantly more experience using spreadsheets, authoring micro-worlds or simulations, making concept maps, modeling complex systems and writing computer programs. A DFA supports the findings of the Mann-Whitney $U$ test with preparing spreadsheets, processing text and making concept maps as the top predictors of gender.

Table 3: Frequency and type of Internet activity (Mann-Whitney $U$ test).

\begin{tabular}{|lccc|ccc|cc|}
\hline & \multicolumn{3}{c|}{ Female } & Male \\
\hline $\begin{array}{l}\text { How often do you use the internet } \\
\text { to: }\end{array}$ & $\mathbf{N}$ & Mean & STDEV & $\mathbf{N}$ & Mean & STDEV & Sig. $\begin{array}{r}\text { Effect } \\
\text { Size (d) }\end{array}$ \\
Search for information & 402 & 4.87 & .44 & 76 & 4.51 & .79 & .000 & .8 \\
Participate in a video-conference & 399 & 1.67 & 1.09 & 76 & 2.29 & 1.37 & .000 & .6 \\
\hline
\end{tabular}

Of the 24 items listed under the frequency and type of Internet activity, only three showed a significant statistic with a medium or large effect size. Table 3 shows that females used the Internet to search for information more often than males did, but participated in video-conferencing less often. A DFA supports the findings of the Mann-Whitney $U$ test with search for information and participating in videoconferencing as the top predictors of gender.

None of the items under the topic of attitudes about using computers and the Internet showed a significant statistical difference with a medium or large effect size. As well, no significant statistical difference between the campus groups was found.

Statistically significant Mann-Whitney $U$ test results with small effect size, while not indicative of a strong relationship between the groups and the effect, are nonetheless interesting and may reveal patterns in relationships. In such cases the findings indicated that men felt more competent than women in using specialized software such as multimedia authoring $(p<.01)$ and web authoring $(p<.01)$, but less confident using a word processor application $(p<.01)$. They used computers to publish materials $(p<.01)$ and create multimedia $(p<.01)$ more often than females, but used email less often $(p<.01)$. 
Men had more experience uploading video to video-sharing sites $(p<.05)$, downloading software/games $(p<.05)$, playing online games $(p<.05)$, working online with others $(p<.026)$, accessing Facebook/MySpace $(p<.05)$ and contributing to or creating a Wiki $(p<.01)$, but less experience than women when it came to accessing blogs or discussion web sites $(p<.05)$. With regards to attitudes, men believed more strongly than women that using computers in their courses was exciting $(p<.05)$.

\section{Discussion}

The findings of this exploration into the differences in ICT competency, use and attitudes of UAE undergraduates in a single-gender educational setting have shown that while women and men share the same attitudes towards the value of ICT in higher education, their experience and habits differ in many ways. Hence, a 'gender digital divide' does exist, albeit not as a rift that portends increasing inequalities, but simply as evidence of a different reality associated with the gender segregation.

Men seem to have a more broad-based experience with ICT. More of them have explored various specialized software applications either outside of the educational context or from participating in high school ICT enrichment schemes. This is reflected in the frequency of usage findings indicating that men showed a greater involvement with applications such as spreadsheets, micro-worlds or simulations, concept maps, complex systems and programming, and more experience with video conferencing. Meanwhile, women appear to have a more in-depth experience with basic software applications that are used to a great extent in an educational context. They show a greater frequency of usage for word processing and accessing the Internet for gathering information: activities strongly related with coursework.

Moreover, Mann-Whitney $U$ test results that were statistically significant, but showed a small effect size, also point to a more eclectic familiarity with ICT among men. They perceive themselves as more competent than women when it comes to multimedia and web authoring. They seem to have more experience in creating desk-top publishing and multimedia materials, and in uploading and downloading materials to the web, playing games and working with others online, and accessing social network sites. Not surprisingly, and possibly because of their almost unrestricted access to ICT, men seem to be better motivated to use computers for their education. These types of results also continue to portray women as having a more constrained experience of ICT. Rather than interacting online with others through social networking and online collaboration, women use email, which provides a "safer", more culturally acceptable way of interacting with others.

\section{Conclusion}

With the advent of ubiquitous ICT, universities throughout the world, including the UAE, are not only considering changes to the way they deliver the curriculum, but also encouraging efforts to make ICT integral to their pedagogy (Bishop \& Doiron, 2003; Yoshida, 2006). In this context, it is not enough to expect students just to be familiar with accessing the internet for information, and with using email, word processors, presentation software and spreadsheets. In order to take full advantage of the affordances, opportunities and pedagogical implications of ICT (John \& Sutherland, 2005), students will increasingly be required to create graphics and concept maps, record and edit audio, shoot and edit video, use web applications, download/upload files from/to the web and work collaboratively online.

The results of this survey clearly indicate that young Emirati men and women are entering UAE universities with different sets of prerequisite knowledge and skills of ICT. While the curriculum objectives should not differentiate by gender, the design of ICT enabled learning activities in coursework 
needs to take the findings of this research into consideration. All foundation level university courses need a review of their ICT competency requirements for coursework and, where possible, a restructuring of learning activities to ensure that ICT not only supports the curriculum objectives, but also focuses on bridging the gender digital divide.

The findings of this research suggest that coursework activities for men should provide them with increased opportunities to practice and strengthen the use of basic applications such as word processing and presentation software. While the findings show that men are more confident with specialized applications and use them more frequently than women do, these levels are still low and need to improve if better self-efficacy levels are to be achieved. Hence, learning activities that involve creating concept maps, computer programs, micro-worlds and simulations, multimedia and web sites, modeling systems and participating in video-conferences should also be considered.

Coursework activities for women, while continuing to make the most of their high levels of competency with word processing and presentation software, should also provide them with the chance to acquaint themselves with specialized applications such as concept mapping, micro-worlds and simulations software, and to use the Internet to work collaboratively with others. Activities that introduce them to modeling systems, writing simple computer programs, creating multimedia and web sites should also be considered.

Furthermore, the socio-cultural dimension of bridging the UAE gender digital divide needs to be explored in greater detail. Some impediments may exist to offering collaborative work through the internet, if such an experience involves interacting with the opposite sex. While research by Shen and Shakir (2009) has shown evidence that access to the Internet has an impact on identity development, they comment that some female students expressed concern about interacting with male students in an online discussion (p. 6).

While the self-reported data in this study is appropriate to the subjective nature of self-efficacy, and enabled the researchers to gain data from a large sample, further research could take into account a possible tendency among women to underplay their own competence with IT (Margolis \& Fisher, 2002), and could relate self-reported data to observation of actual IT use (cf. Varma, 2010). It is also important to note that the present survey questionnaire has provided only one snapshot in time. Because of continuing transformation at all levels of the UAE education system, there is a need for further research into single-gender undergraduate education and ICT self-efficacy. Changes in the gender profile need to be monitored to ensure that women, who make up more than $70 \%$ of the 34,722 student population enrolled in the UAE's national tertiary education institutions in 2010/2011 (United Arab Emirates National Bureau of Statistics, 2011), become as confident and as skilled at using computers, and as experienced at working online with others, as their male counterparts.

\section{References}

Bishop, G. D. \& Doiron, G. (2003). Using online forums as a replacement for face-to-face discussion groups. Proceedings of FASS-CDTL Symposium: Grounded Experiences in University Teaching and Learning, 36-43. National University of Singapore, Singapore.

Cassidy, S. \& Eachus, P. (2002). Developing the computer user self-efficacy (CUSE) scale: Investigating the relationship between computer self-efficacy, gender and experience with computers. Journal of Educational Computing Research, 26(2), 133-153.

Coe, R. (2002). It's the effect size, stupid - What effect size is and why it is important. In proceedings of the British Educational Research Association Annual Conference, Exeter, England. 
Cohen, J. (1988). Statistical power analysis for the behavioral sciences (2nd ed.). New Jersey: Lawrence Erlbaum.

Dhakal, S. P. (2009). The digital divide and gender: a survey of environmental community organizations' leaders in Perth, Western Australia. Community Informatics, 5(3) and 6(1). Retrieved 15/03/2012 http://ci-journal.net/index.php/ciej/article/view/524/511

DiMaggio, P., Hargittai, E., Celeste, C. \& Shafer, S. (2004). Digital inequality: from unequal access to differentiated use. Social Inequality, edited by Kathryn Neckerman, 355-400, Russell Sage Foundation, New York

Dunlap, W. P., Cortina, J. M., Vaslow, J. B. \& Burke, M. J. (1996). Meta-analysis of experiments with matched groups or repeated measures designs. Psychological Methods, 1, 170-177.

Eachus, P. \& Cassidy, S. (2004). Development of the Web Users Self-Efficacy Scale (WUSE). In proceedings of the 2nd Education in a Changing Environment Conference, University of Salford, September 2004.

Fay, M. P. \& Proschan, M. A. (2010). Wilcoxon-Mann-Whitney or t-test? On assumptions for hypothesis tests and multiple interpretations of decision rules. Statistics Surveys 4, 1-39

Hafkin, N. \& Huyer, S. (2006). Cyberella or Cinderella? Empowering women in the knowledge society. New Hampton: Kumarian Press.

Hargittai, E. \& Shafer, S. (2006). Differences in actual and perceived online skills: the role of gender. Social Science Quarterly, 87(2), 432-448.

Huyer, S. \& Mitter, S. (2003). ICT's, globalisation and poverty reduction: gender dimensions of the knowledge society (part I). Poverty Reduction, Gender Equality and the Knowledge Society: Digital Exclusion or Digital Opportunity? Accessed 15 March 2012 at http://unpan1.un.org/intradoc/groups/public/documents/unpan/unpan037351.pdf

John, P. \& Sutherland, R. (2005). Affordance, opportunity and the pedagogical implications of ICT. Educational Review, 57(4), 405-413.

Klecka, W. R. (1980). Discriminant analysis. Quantitative Applications in the Social Sciences Series, 19. Thousand Oaks, CA: Sage Publications.

Laforge, H. (1981). Analyse multivariée pour les sciences socials et biologiques avec application des logiciels BMP, BMDP, SPSS, SAS. Ed. Etudes Vivantes, Montréal, Canada.

Margolis, J. \& Fisher, A. Unlocking the clubhouse: women in computing. Cambridge, MA: MIT Press.

Martin, C. D. (2005). Removing the veil: Personal reflections on educating women in Dubai. ACM SIGCSE Bulletin, 37(4), 30-33.

Milis, K., Wessa, P., Poelmans, S., Doom, C. \& Bloemen, E.(2008). The Impact of gender on the acceptance of Virtual Learning Environments. In proceedings of the International Conference of Education, Research and Innovation, Madrid, Spain, 2008.

Sam, H. K., Othman, A. E. A. \& Nordin, Z. S. (2005). Computer Self-Efficacy, Computer Anxiety, and Attitudes toward the Internet: A Study among Undergraduates in Unimas. Educational Technology \& Society, 8 (4), 205-219. 
Shakir, M., Shen, K.,Vodanovich, S. \& Urquhart, K. (2008). Exploring women's experience of IT in the UAE. In Proceedings of the European and Mediterranean Conference on Information Systems (EMCIS). Dubai, UAE, pp. 1-10.

Shen, K. \& Shakir, M. (2009). Internet usage among Arab adolescents : Preliminary findings In proceedings of the European and Mediterranean Conference on Information Systems (EMCIS), Izmir, Turkey 1-10

United Arab Emirates National Bureau of Statistics. (2011). Statistic report - Education 2009/2010. Retrieved 15/03/2012 at http://www.uaestatistics.gov.ae/ReportDetailsEnglish/tabid/121/Default.aspx?ltemld=1963\&PTID=104 \&Menuld $=1$

United Nations (2005). Gender equality and empowerment of women through ICT. UN Division for the Advancement of Women, Department of Economic and Social Affairs. Accessed 15 March 2012 at http://www.un.org/womenwatch/daw/public/w2000-09.05-ict-e.pdf

Torkzadeh, G. \& Koufteros, X. (1994). Factorial validity of a computer self-efficacy scale and the impact of computer training. Educational and Psychological Measurement, 54 (3), 813-921.

Tubaishat, A., Bhatti, A. \& El-Qawasmeh, E. (2006). ICT Experiences in Two Different Middle Eastern Universities. Journal of Issues in Informing Science and Information Technology, 3, 667-678.

Usoro, A. \& Abid, A. (2006). Factors affecting the use of computerised strategic planning tools (SPT): measures development. Journal of Information Science and Technology, 3(1), 33-56.

Varma, R. (2010). Computing self-efficacy among women in India. Journal of Women and Minorities in Science and Engineering, 16, 257-274. Accessed 12 August 2012 at

http://www.unm.edu/ varma/print/JWMSE_CS\%20Self\%20Efficacy.pdf

Vodanovich, S., Urquhart, C. \& Shakir, M. (2010). Same but Different: Understanding Women's Experience of ICT in the UAE. The Electronic Journal of Information Systems in Developing Countries, 40(4), 1-21.

Yoshida, M. (2006). Towards ubiquitous learning and education. In proceedings of the 6 th Distance Learning and the Internet, Vladivostok, Russia.

Zineddine, M. \& Kindi, H. (2011). The Status of Emirati Women in the ICT Sector. In Proceedings of the International Conference on Technology and Business Management. Dubai, UAE. 


\section{Appendix: The survey questionnaire}

How competent are you with the

following: (Please fill the circle)

Word processing (e.g., Word)

Databases (e.g., Access)

Spreadsheets (e.g., Excel)

Graphics (e.g., Paint, Photoshop)

Multimedia authoring (e.g., HyperStudio)

Presentation software (e.g., PowerPoint)

Internet

Concept mapping (e.g., Inspiration)

Email

Publishing software (e.g., Publisher)

Webpage authoring (e.g., Dreamweaver)

Programming languages (e.g., C, Java )

Modeling software (e.g., Model-It, Stella)

Do you use the computer to:

Play games (e.g., FIFA, Solitaire)

Make presentations (e.g., PowerPoint)

Process text (e.g., Word)

Publish materials (e.g., Publisher)

Prepare spreadsheets (e.g., Excel)

Create graphics

Communicate (e.g., email)

Access the Internet

Develop web pages

Develop multimedia

Author microworlds/simulations

Make concepts maps

$\begin{array}{ccccc}\begin{array}{c}\text { Cannot } \\ \text { use it }\end{array} & \begin{array}{c}\text { Use it to a } \\ \text { small } \\ \text { extent }\end{array} & \begin{array}{c}\text { Use it } \\ \text { satisfactorily }\end{array} & \begin{array}{c}\text { Use it } \\ \text { well }\end{array} & \begin{array}{c}\text { Use it } \\ \text { very } \\ \text { well }\end{array} \\ & & & & \end{array}$

(1) (2) (3) (4) (5)

(1) (2) (3) (4) (5)

(1) (2) (3) (4) (5)

(1) (2)

(3) (4)

(1) (2)

(3)

(5)

(1) (2)

(3)

(1)

(2)

(3)

(2)

(3)

(1)

(2)

(3)

(1)

(2)

(3)

(5)

(1) (2)

(3)

(2)

(3)

(1) (2)

(3)

(5)

1 or 2

times per week

(4)

(4)

(4)

(4)

(4)

(4)

(4)

(4)

(4)

(1)

(2)

(3)

(1) (2)

(3)

(4)

(1)

(2)

(3)

(4)

(5)

(1) (2)

(3)

(4)

(5) 
Model complex systems

Write a computer program

Use educational CD
(1)

(1)

(1)
(2)

(2)

(2)
(3)

(3)

(3)
(4)

(4)

(4)
(5)

(5)

(5)
How often do you use the internet to:

Chat online with friends

Search for information (e.g., Google)

Shop for yourself/others

Do your banking

Access local newspapers online

Access foreign newspapers online

Listen to online radio stations

Browse video-sharing (e.g., YouTube)

Upload video to video-sharing site

Download video/movies/TV shows

Download music

Download software/games

Upload pictures to online sharing site

Work with others (e.g., Google Docs)

Access Twitter

Access Facebook/MySpace

Access Blog or discussion web sites

Contribute to a Blog or discussion

Access Wikis/Wikipedia

Contribute to or create a Wiki

Access Blackboard to download files

Access Blackboard to submit assignments

Participate in a video-conference

Play online games
Never

(1)

(1)

(1)

(1)

(1)

(1)

(1)

(1)

(1)

(1)

(1)

(1)

(1)

(1)

(1)

(1)

(1)

(1)

(1)

(1)

(1)

(1)

(1)

(1)

\section{1 or 2 times per semester}

(2)

(2)

(2)

(2)

(2)

(2)

(2)

(2)

(2)

(2)

(2)

(2)

(2)

(2)

(2)

(2)

(2)

(2)

(2)

(2)

(2)

(2)

(2)

(2)
(3)

(3)

(3)

(3)

(3)

(3)

(3)

(3)

(3)

(3)

(3)

(3)

(3)

(3)

(3)

(3)

(3)

(3)

(3)

(3)

(3)

(3)

(3)

(3)
1 or 2 times per week

(4)

(4)

(4)

(4)

(4)

(4)

(4)

(4)

(4)

(4)

(4)

(4)

(4)

(4)

(4)

(4)

(4)

(4)

(4)

(4)

(4)

(4)

(4)

(4)
Almost every day

(5)

(5)

(5)

(5)

(5)

(5)

(5) 
How do you feel about using computers and the Internet?

I feel comfortable with using computer in my courses.

Using computers in my courses stresses me out.

If something goes wrong with my computer, I will not know how to fix it.

Using the computer in my courses excites me

Using the computer in my courses scares me.

The computer is a valuable tool for students.

The computer will improve the way I learn.

The computer does not help me learn because it is not easy to use.

The computer helps me learn because it allows me to express my thinking in better/different ways.

The computer helps teachers to teach in more effective ways.

The computer does not help teachers to teach because it creates technical problems.

I feel comfortable with using the Internet.

Using the Internet in my courses stresses me out.

Using the Internet in my courses excites me.

Using the Internet in my courses scares me.

The Internet is a valuable tool for students.

Using the Internet will improve the way I

learn.

Using the Internet does not help me learn.

I can quickly find information on the Internet.

It takes me a lot of effort and time to find information on the Internet.

Using the Internet helps me understand concepts.

Using the internet is confusing because there is too much information.
Strongly

Disagree

(1)

(1)

(1)

(1)

(1)

(1)

(1)

(1)

(1)

(1)

(1)

(1)

(1)

(1)

(1)

(1)

(1)

(1)

(1)

(1)

(1)

(1)
Disagree Neutral Agree

(2)

(3)

(4)

(3)

(4)

(5)

(3)

(4)

(5)

(3) (4)

(5)

(3)

(4)

(5)

(3)

(4)

(5)

(3) (4)

(5)

(3) (4)

(5)

(3) (4)

(5)

(5)

(5)

(5)

(5)

(5)

(5)

(5)

(5)

(5)

(5)

(5)

(5)

(5) 